\title{
MAKE SURE THE JOURNAL REACHES YOU
}

This is the last issue of the ICCA Journal to appear in 1995. Your membership has formally expired by December 31, 1995. In 1995 you should have received four Journals as due to you under your membership. In order to receive all issues of the 1996 Journal, you should subscribe as an ICCA member. The (renewal) fee is now Dutch florins (Hfl.) 60.--, UK $£ 25$.-- or US $\$ 40 .--$. The setting of the annual fee has been agreed upon at the Triennial Meeting in Hong Kong in June 1995. For subscriptions, renewals and orders of back issues, readers in North America and the United Kingdom should send their orders and payment to

\author{
ICCA \\ c/o D.F. Beal \\ Dept. of Computer Science, Queen Mary and Westfield College \\ Mile End Road, London E1 4NS / England \\ Email: icca@dcs.qmw.ac.uk
}

Payment may be made as follows: UK pounds or US dollars, cash; cheques for UK pounds, from a UK bank account, or Eurocheque only; cheques for US dollars, from a North American bank.

For all other subscriptions, renewals and orders of back issues, readers should send their orders and payment to

ICCA

c/o Prof.dr H.J. van den Herik

University of Limburg, Dept. of Computer Science

P.O. Box 616, $6200 \mathrm{MD}$ Maastricht / The Netherlands

Email: icca@cs.rulimburg.nl

Payment may be made as follows: Dutch guilders, cash or Eurocheque: Hfl. 60.--; Dutch guilders, direct bank transfer from abroad: Hfl. 75.--; all other cheques: Hfl. 80.--.

Though it is primitive, valid banknotes in UK pounds, US dollars, or Dutch guilders are still the most effective way of paying your dues neatly and safely. Also it is the cheapest way to transfer your dues free of all charges to the ICCA. Of course, postal regulations require that banknotes are sent by registered mail.

For the convenience of readers in countries allowing direct transfer to Dutch banks, payment may be made to the ABN/AMRO bank, account no. 450790878 , Helmstraat, Maastricht. If desired, a transfer to postal giro account no. 1050085 of the ABN/AMRO bank is acceptable, provided the ABN/AMRO account number and the name of the ICCA are mentioned. While being acceptable, this method imposes charges on the ICCA and payment should be increased by Dfl. 15.-- to compensate.

It is vital that the cheque either be from a bank of the same country as the currency, or be a Eurocheque. International money orders are acceptable only if made out to Prof.dr H.J. van den Herik by name. We regret that no other form of payment is acceptable.

Please include a correct statement of your mailing address. (We keep receiving payments without addresses!) Should your mailing label be erroneous or when changing residence, please return an amended label to Don Beal or Prof.dr Van den Herik as the case may require. Those using Eurocheques for their payment are requested to fill in the 4-digit validation number on the back of their cheques. Otherwise, we cannot cash them.

While stocks last, back issues of the ICCA Journal as from Vol. 6, No. 3 (August 1983) up to Vol. 18, No. 4 are still available at US \$ 8.-- each, US \$ 25.-- for any four, and US \$ 280.-- for the set up to Vol. 18 , No. 4. Please order these as you would order or renew a subscription.

Institutional Membership is at US \$ 160.-- per year and includes six copies of each issue of the Journal. Library subscriptions are US \$ 80.-- per year. A replacement copy for libraries is rated at US \$20.-- including handling and mailing. 


\section{ADDRESSES OF AUTHORS}

Wilhelm Barth

Institut für Computergraphik

Technische Universität Wien

Resselgasse 3

A-1040 Wien / Austria

Don Beal / Martin Smith

Dept. of Computer Science

Queen Mary and Westfield College

London University

Mile End Road

London E1 4NS / England

Igor Botvinnik

Chess Computer Center

Gogolevsky Blvd 14

Moscow / Russia

Christopher Chabris

HCC Associates

P.O. Box 2967

Harvard Square Station

Cambridge, MA 02238 / USA

Steven Edwards

P.O. Box 215

Chelmsford, MA 01824 / USA

Ken-ichi Handa / Hiroyuki Iida

Electrotechnical Laboratory

Tsukuba / Japan

Rainer Feldmann / Ulf Lorenz

University of Paderborn

Dept. of Mathematics and Computer Science

33095 Paderborn / Germany
Bob Herschberg

Delft University of Technology

Dept. of Computer Science

Julianalaan 132

2628 BL Delft / The Netherlands

Göran Grottling

Diabasvägen 3

S-43732 Lindome / Sweden

Thoralf Karlsson

Uttermarksgatan 31C

S-63351 Eskilstuna / Sweden

Monty Newborn

McGill University

School of Computer Science

805 Sherbrooke St. West

Montreal, Quebec H3A 2K6 / Canada

Theo van der Storm / Hansje Weijer

Wethouder Driessenstraat 5

1107 XG Amsterdam ZO / The Netherlands

Jos Uiterwijk

University of Limburg

Dept. of Computer Science

P.O. Box 616

6200 MD Maastricht / The Netherlands

The addresses of authors not mentioned above will be found elsewhere in this issue.

The deadline for copy for the next issue is February 1, 1996.

Please submit contributions and correspondence to:

\begin{tabular}{|c|c|}
\hline \multicolumn{2}{|l|}{ Prof. dr H.J. van den Herik } \\
\hline \multicolumn{2}{|l|}{ University of Limburg } \\
\hline \multicolumn{2}{|c|}{ Faculty of General Sciences } \\
\hline \multicolumn{2}{|c|}{ Department of Computer Science } \\
\hline \multirow[t]{2}{*}{ Correspondence address: } & P.O. Box 616 \\
\hline & 6200 MD Maastricht / The Netherlands \\
\hline \multirow[t]{2}{*}{ Residential Address: } & St. Jacobstraat 6 \\
\hline & 6211 LB Maastricht / The Netherlands \\
\hline Telephone: & +31433883477 \\
\hline Email: & icca@cs.rulimburg.nl \\
\hline Fax: & +31433252392 \\
\hline
\end{tabular}

Intending contributors from the US or Canada may submit their copy to Professor Marsland, University of Alberta, Department of Computing Science, Edmonton, Alberta T6G 2H1 Canada.

Please address all material to be reviewed, digested or abstracted, when in English, to Professor Marsland, when in other languages to Dap Hartmann, Center for Astrophysics, 60 Garden Street, Cambridge MA. 02138, USA. 